\title{
Comsol Simulation of Laser Welding of Aluminum
}

\author{
Ivaylo Balchev \\ Rezekne Academy of Technology \\ Rezekne, Latvia \\ Ivaylo.Balchev@rta.lv \\ Erika Teirumnieka \\ Rezekne Academy of Technology, \\ Rezekne, Latvia \\ Erika.Teirumnieka@rta.lv
}

\author{
Lyubomir Lazov \\ Rezekne Academy of Technology \\ Rezekne, Latvia \\ Lyubomir.Lazov@rta.lv
}

\author{
Nikolay Angelov \\ Technical University of Gabrovo \\ Gabrovo, Bulgaria \\ angelov_np@abv.bg
}

\begin{abstract}
This research includes a Comsol Mutiphysics model describing the temperature distribution on aluminum during the laser conductivity welding process. The influence of laser power and speed on the welding process is discussed and compared with experiments. Numerical simulations of laser welding process have been performed to determine the temperature fields of laser impact to samples of aluminum. Numerical calculations are made for fiber laser. The plots of the temperature dependence on the surface and in the depth of aluminum samples on the velocity are analyzed for several power densities for this laser.
\end{abstract}

Keywords - laser welding, comsol multiphysics, aluminium, automotive industry, fibre laser

\section{INTRODUCTION}

The investigation of the temperature distribution in a material induced by laser radiation is very important for the optimization of different industrial laser material processing like cutting, drilling, marking, or welding.

Laser welding technology is popular in the automotive industry, where it is used in the production of a large number of parts due to its high welding speed, low energy input and the resulting low part distortion, ease of automation, and other benefits [1]. Meanwhile, aluminium is steadily growing in automotive use to lighten car components. It is considered "material of choice" to meet the challenge of reducing environmental footprints and improving fuel economy while still retaining the security of automobiles. Despite the good prospects, joining aluminium using this technique can be problematic at present in terms of weld quality.

Laser welding of light and high reflective metals such as aluminium is a very difficult technological process in particular, it requires extreme precision and selection of the correct laser source and technological parameters to ensure a quality welding seam. That is why it is necessary to use physical modelling and simulations as a powerful tool for clarifying the fundamental aspects of the laser welding process and for preliminary assessment and engineering forecasts of the emerging effects and for correct choice of the optimal working range of the technological parameters in the process of laser welding [2 - 5], [6 - 10], [14].

There are two types of heating modes, conduction and keyholes mode. They are used to describe the resulting melting of the metal during laser welding process. The power density applied to the welding area is the main difference between these two modes. Conduction welding takes place when the intensity is sufficient to cause meting but not sufficient to cause boiling [11 - 13].

In this article, a theoretical model describing the process of laser conduction welding of aluminum has been developed. The numerical simulation methods used in this research provide a good evaluation of both the optimum technical parameters, such as output laser power and speed of beam, as well as the dynamics of the process and the thermal isotherms in the processing area. 


\section{RESEARCH METHODOLOGY}

In order to approximate the depth and width of a welding zone, a computer simulation of the laser welding process was conducted using the commercial finite element method (FEM) software package COMSOL Mutiphysics. The laser beam was simulated as a moving heat source whose profile was represented by vertical configuration of Hermite-Gaussian mode (TEM01). The simulation was performed for the purpose of moving the laser beam over the surface of the workpiece in a straight line. The heating due to laser is treated as a body heat source on the surface. The body heat load within the workpiece plate is given by the following expression:

$Q(x, y, z)=\mathrm{Q}_{0}\left(1-\mathrm{R}_{\mathrm{c}}\right) \cdot \frac{A_{c}}{\pi \sigma_{x} \sigma_{y}} e^{-\left[\frac{\left(x-x_{0}\right)^{2}}{2 \sigma_{x}^{2}}+\frac{\left(y-y_{0}\right)^{2}}{2 \sigma_{y}^{2}}\right]} \cdot e^{-A_{c} z}$

$\mathrm{Q}_{0}$ is total input power, $\mathrm{R}_{\mathrm{c}}-$ reflection coefficient, $\sigma_{\mathrm{x}}$ and $\sigma_{\mathrm{y}}$ are the standard deviation parameters which determine the beam width and astigmatism.

\section{A. Welding process thermal model}

The amount of energy that is absorbed from the target material is much lower than the amount of energy that transfers the laser beam as it is generated from the laser beam machine, due to reflection coefficient and energy losses that take place during the process. In order to examine welding process the schema of the heating process shown in Fig. 1. The target material is in liquid phase which means that the temperature is above the melting temperature but has not reached the evaporating temperature. The amount of the total power that is absorbed is calculated the same way as before using the reflectivity coefficient of the material at melting phase:

$Q=\mathrm{Q}_{0}\left(1-R_{\text {melt }}\right), \quad \mathrm{T}_{\text {melt }} \leq \mathrm{T}<\mathrm{T}_{\text {evap }}$

where $\mathrm{Q}$ is the absorbed energy flux, $\mathrm{Q}_{0}$ is the incidence laser beam heat flux, $\mathrm{R}_{\text {melt }}$ is the reflectivity of the target material at liquid phase, $\mathrm{T}_{\text {melt }}$ is the material melting temperature, and $\mathrm{T}_{\text {evap }}$ is the material evaporating temperature.

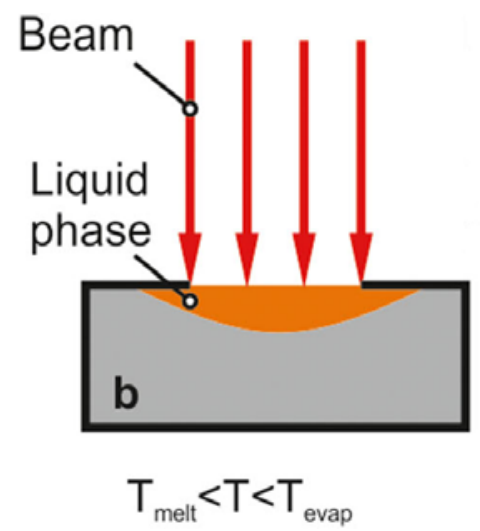

Fig. 1. Welding process thermal modelling

\section{B. Initial-boundary conditions and heat transfer model}

The top face of the 3D solid body used in the simulation was set to be the target face for the incidence laser beam pulses, and the geometry was set to be a rectangular block with dimensions $\mathrm{WxDxH}$. The initial temperature of the solid body $T_{0}$ was set to be equal to the ambient temperature $\left(\mathrm{T}_{0}=\mathrm{Tamb}=20^{\circ} \mathrm{C}\right)$ in terms of the initial and boundary conditions. The following version of the heat equation is used to model heat transfer in a solid body:

$\rho C_{p} \frac{\partial T}{d t}+\nabla \vec{q}=\mathrm{Q}, \quad \overrightarrow{\mathrm{q}}=-k \nabla T$

where $\rho$ is the density of the material, $C_{p}$ - heat capacity, $\mathrm{k}$ - thermal conductivity, $\mathrm{Q}$ is the heat source.

The focal spot of the laser radiation focuses on the surface of the body, so it is assumed that the heat source is on the surface.

A moving heat flux with a 2D Gaussian (4) density distribution is used as the laser beam. The expression for 2D Gaussian can easily be obtained as the product of $1 \mathrm{D}$ Gaussian (3) on the $\mathrm{x}$ and $\mathrm{y}$ axes

$g_{\sigma}(x)=\frac{1}{\sqrt{2 \pi \sigma}} \exp \left(-\frac{x^{2}}{2 \sigma^{2}}\right)$
$G_{\sigma}(x, y)=g_{\sigma}(x) \cdot g_{\sigma}(y)=\frac{1}{\sqrt{2 \pi \sigma^{2}}} \exp \left(-\frac{x^{2}+y^{2}}{2 \sigma^{2}}\right)$

TABle 1. Chemical Compositions of Aluminum Alloys

\begin{tabular}{|c|c|}
\hline Element & Percent \\
\hline $\mathrm{Si}$ & 0.06 \\
\hline $\mathrm{Fe}$ & 0.16 \\
\hline $\mathrm{Cu}$ & 1.25 \\
\hline $\mathrm{Mn}$ & 0.08 \\
\hline $\mathrm{Mg}$ & 2.32 \\
\hline $\mathrm{Zn}$ & 5.47 \\
\hline $\mathrm{Cr}$ & 0.20 \\
\hline $\mathrm{Ti}$ & 0.01 \\
\hline $\mathrm{Ga}$ & 0.01 \\
\hline $\mathrm{V}$ & 0.01 \\
\hline $\mathrm{Al}$ & 90.41 \\
\hline
\end{tabular}

The discretization of the sample was performed by triangular finite elements with maximum element size 0.6 , minimum element size 0.1 , maximum element growth rate 1.9 (Fig. 2).

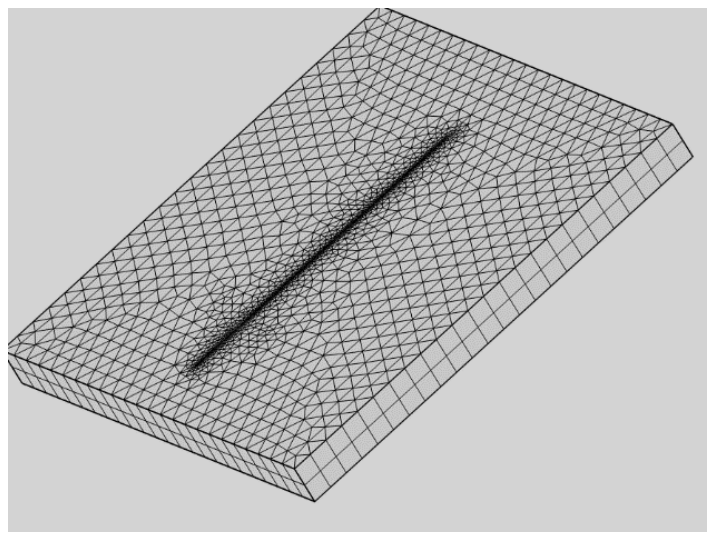

Fig. 2. Discretization of welded samples 
The input data for numerical experiments is mentioned in Table 2.

TABLE 2. THERMAL AND PHYSICAL PROPERTIES OF THE ALUMIMUM $7075-\mathrm{T} 6$.

\begin{tabular}{|l|c|}
\hline \multicolumn{1}{|c|}{ Properties } & Value \\
\hline Melting point $T_{m},{ }^{0} \mathrm{C}$ & 600 \\
\hline Boiling point $T_{v},{ }^{0} \mathrm{C}$ & 2450 \\
\hline Thermal conductivity coefficient $\mathrm{k}, \mathrm{W} /(\mathrm{m} . \mathrm{K})$ & 150 \\
\hline Density $\rho, \mathrm{kg} / \mathrm{m}^{3}$ & 2800 \\
\hline Specific heat capacity $c, \mathrm{~J} /(\mathrm{kg} . \mathrm{K})$ & 826 \\
\hline Thermal diffusivity coefficient a, $\mathrm{m}^{2} / \mathrm{s}$ & $23.4 \times 10^{-6}$ \\
\hline
\end{tabular}

The numerical simulations of our study were divided into two main series:

The power is maintained at a constant value of 1500 watts, and the diameter of the focal spot on the surface is changed in the range from 0.75 to $1 \mathrm{~mm}$ and the welding speed in the range from 25 to $125 \mathrm{~mm} / \mathrm{s}$. In the second series of computer simulations, the power is fixed at 2500 watts, and the upper parameters of the laser radiation are changed at the same operating intervals.

\section{RESULTS AND DISCUSSIUON}

The Comsol Multiphysics software was used to conduct a number of numerical experiments. The speed of welding and the power of the laser were changed.

The Fig. 3 shows specific temperature distribution in the plane $\mathrm{x}$ and $\mathrm{y}$, obtained from numerical calculations for the welding speed $v=25 \mathrm{~mm} / \mathrm{s}$ and laser power 1500 W.

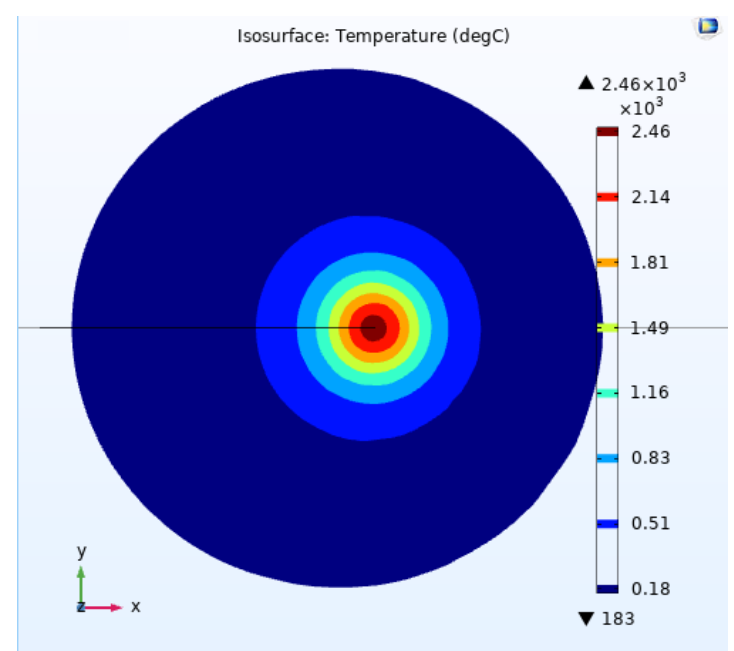

Fig. 3. Temperature field on the surface of aluminium for laser power $\mathrm{P}=1.5 \mathrm{~kW}$ and speed $\mathrm{v}=25 \mathrm{~mm} / \mathrm{s}$.

Fig. 4 and Fig. 5 shows graphs of the dependence of the depth of the welding pool on the speed for two diameters of the working spot $d_{1}=0.75 \mathrm{~mm}$ and $d_{2}=1.00 \mathrm{~mm}$, respectively. The analysis of the results allows to draw the following conclusions:

- As the welding speed increases, the depth of the pool decreases non linearly for the four obtained graphic dependencies;
- $\quad$ The average rate of depth reduction for diameter $d_{1}=0.75 \mathrm{~mm}$ is

$9.3 \mu \mathrm{m} /(\mathrm{mm} / \mathrm{s})$ for power $P_{1}=1.5 \mathrm{~kW}$;

$15.5 \mu \mathrm{m} /(\mathrm{mm} / \mathrm{s})$ for power $P_{2}=2.5 \mathrm{~kW}$;

for diameter $d_{2}=1.00 \mathrm{~mm}$ is

$8.0 \mu \mathrm{m} /(\mathrm{mm} / \mathrm{s})$ for power $P_{1}=1.5 \mathrm{~kW}$;

$11.1 \mu \mathrm{m} /(\mathrm{mm} / \mathrm{s})$ for power $P_{2}=2.5 \mathrm{~kW}$;

- The depth of the pool for diameter $d_{1}=0.75 \mathrm{~mm}$ is about $40 \%$ greater than the depth of the pool for diameter $d_{2}=1.00 \mathrm{~mm}$.

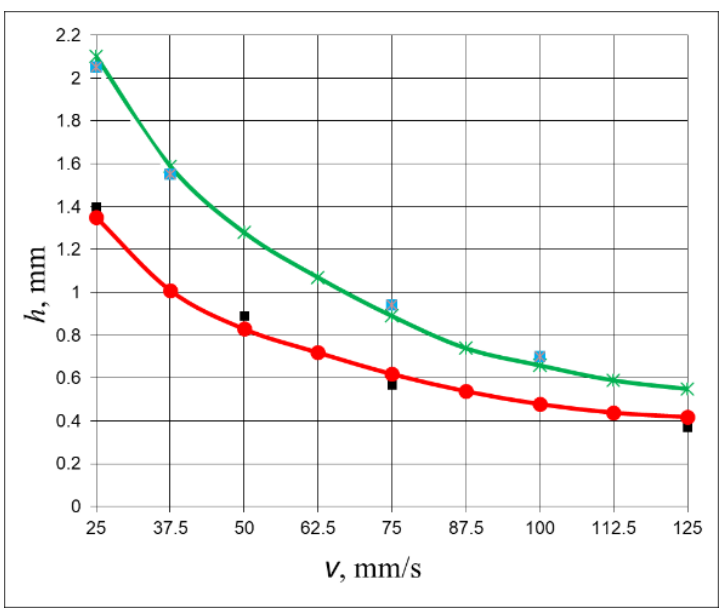

Fig. 4. Dependence of the depth $\mathrm{h}$ on the welding speed $\mathrm{v}$ for a diameter of the working spot $\mathrm{d}_{1}=0.75 \mathrm{~mm}$ and powers: $\mathrm{P}_{1}=1.5 \mathrm{~kW}$ (red colour), $\mathrm{P}_{2}=2.5 \mathrm{~kW}$ (green colour).

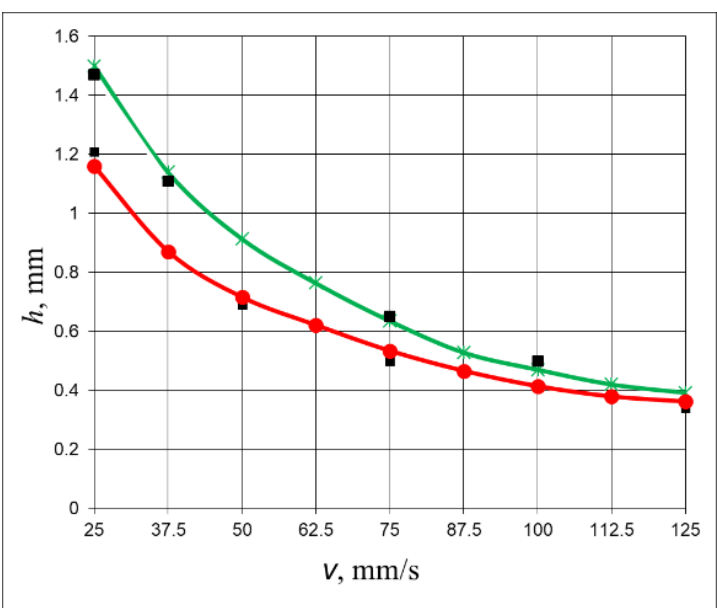

Fig. 5. Dependence of the depth $h$ on the welding speed $v$ for a diameter of the working spot $\mathrm{d}_{2}=1.00 \mathrm{~mm}$ and powers: $\mathrm{P}_{1}=1.5 \mathrm{~kW}$ (red colour), $\mathrm{P}_{2}=2.5 \mathrm{~kW}$ (green colour).

Fig. 6 presents graphs of the dependence of the depth $h$ on the speed $v$ for a power $P_{2}=2.5 \mathrm{~kW}$ and diameters of the working spot $d_{1}=0.75 \mathrm{~mm}$ and $d_{2}=1.00 \mathrm{~mm}$. The following conclusions can be drawn from them:

- As the welding speed increases, the depth of the bath decreases non linearly for both diameters. The curves for speed interval $v \in[25 ; 62.5] \mathrm{mm} / \mathrm{s}$ are steeper than the curves for speed interval $v \in$ [62.5; 125] mm/s; 
- The depth of the pool varies from $0.67 \mathrm{~mm}$ to $2.10 \mathrm{~mm}$ for diameter $d_{1}=0.75 \mathrm{~mm}$ and from $0.39 \mathrm{~mm}$ to $1.50 \mathrm{~mm}$ for diameter $d_{2}=1.00 \mathrm{~mm}$.

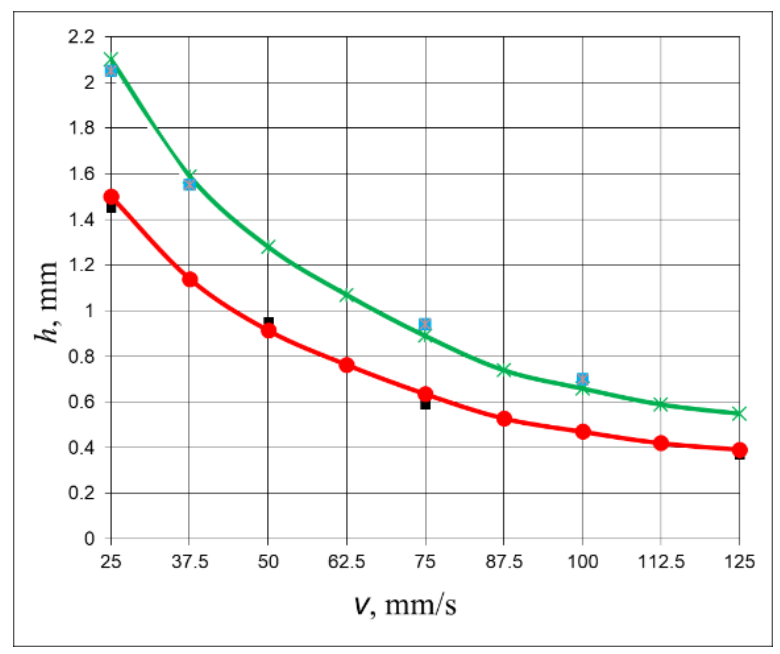

Fig. 6. Dependence of the depth $h$ on the welding speed $v$ for a power $P_{2}=2.5 \mathrm{~kW}$ and diameters of the working spot: $d_{1}=0.75 \mathrm{~mm}$ (green colour); $d_{2}=1.00 \mathrm{~mm}$ (red colour)

Fig. 7 and Fig. 8 shows graphs of the dependence of the width of the welding pool on the speed for two diameters of the working spot $d_{1}=0.75 \mathrm{~mm}$ and $d_{2}=1.00 \mathrm{~mm}$, respectively. It follows from these graphs:

- As the welding speed increases, the depth of the pool decreases non linearly for all obtained graphic dependencies;

- $\quad$ The curves for speed interval $v \in[25 ; 62.5] \mathrm{mm} / \mathrm{s}$ are again steeper than the curves for speed interval $v \in[62.5 ; 125] \mathrm{mm} / \mathrm{s}$;

- The average rate of width reduction for diameter $d_{1}=0.75 \mathrm{~mm}$ is

$17.6 \mu \mathrm{m} /(\mathrm{mm} / \mathrm{s})$ for power $P_{1}=1.5 \mathrm{~kW}$;

$24.0 \mu \mathrm{m} /(\mathrm{mm} / \mathrm{s})$ for power $P_{2}=2.5 \mathrm{~kW}$;

for diameter $d_{2}=1.00 \mathrm{~mm}$ is

$20.5 \mu \mathrm{m} /(\mathrm{mm} / \mathrm{s})$ for power $P_{1}=1.5 \mathrm{~kW}$;

$29.5 \mu \mathrm{m} /(\mathrm{mm} / \mathrm{s})$ for power $P_{2}=2.5 \mathrm{~kW}$;

- $\quad$ The width of the pool for diameter $d_{2}=1.00 \mathrm{~mm}$ is about $25-30 \%$ greater than the depth of the pool for diameter $d_{1}=0.75 \mathrm{~mm}$;

- $\quad$ The width of the pool for power $P_{2}=2.5 \mathrm{~kW}$ is about $40 \%$ greater than the depth of the pool for $P_{1}=1.5 \mathrm{~kW}$ for speed $v=25 \mathrm{~mm} / \mathrm{s}$ and about $25 \%$ greater than the depth of the pool for $P_{1}=$ $1.5 \mathrm{~kW}$ for speed $v=125 \mathrm{~mm} / \mathrm{s}$.

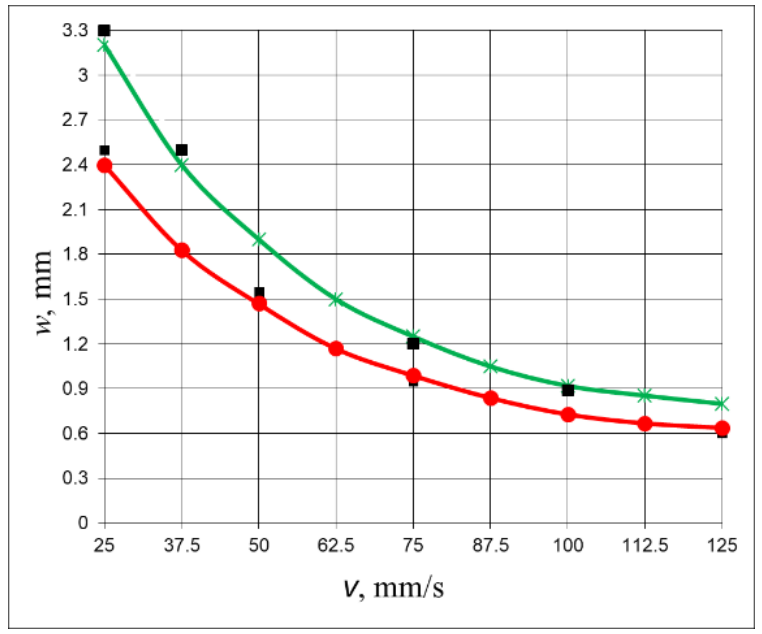

Fig. 7. Dependence of the width $w$ on the welding speed $v$ for a diameter of the working spot $d_{1}=0.75 \mathrm{~mm}$ and laser power: $P_{1}=1.5$ $\mathrm{kW}$ (red colour) and $P_{2}=2.5 \mathrm{~kW}$ (green colour).

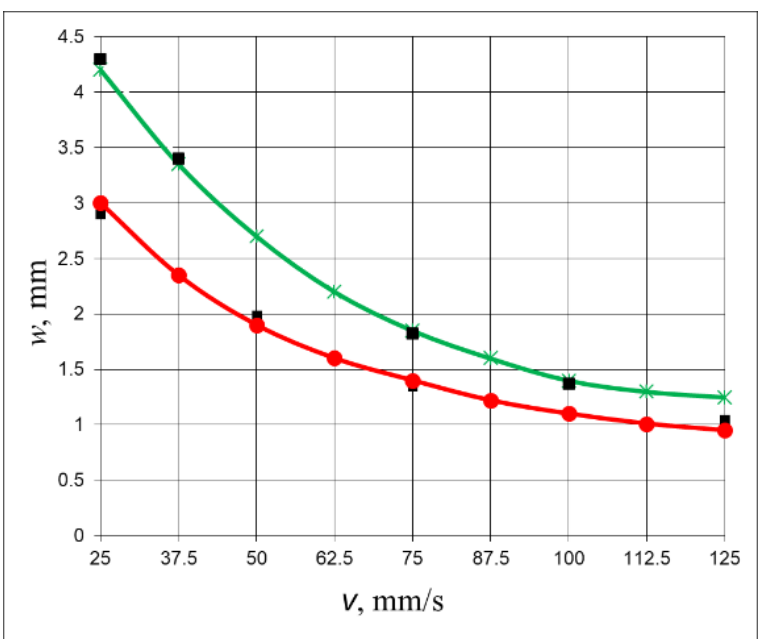

Fig. 8. Graphs of the dependence of the width $w$ on the welding speed $v$ for a diameter of the working spot $d_{2}=1.00 \mathrm{~mm}$ and laser power: $P_{1}=$ $1.5 \mathrm{~kW}$ (red colour) and $P_{2}=2.5 \mathrm{~kW}$ (green colour).

A good coherence of all experimental results with the results of numerical experiments is obtained.

\section{IV.CONCLUSION}

Our current study is an attempt to make little progress in the direction of optimization and implementation of model and simulation approaches in solving a specific technological process for laser welding of aluminium sheets. The study will help speed up the entry of laser technology and more accurate than that for welding in such industries as mechanical engineering, aerospace, automotive medicine, and others.

Due to their unique characteristics, laser welding is increasingly being used in industry today, especially for the production of value-added components that are difficult to produce using traditional welding methods.

Several synergistic factors will contribute to improving the quality and reliability of welds while reducing productivity and production costs. 
These include continuous improvements in the use of appropriate software for modelling, simulations, and process optimization. The growing volume of research in this direction will ultimately contribute to the deeper penetration of laser technologies in the market of new innovative, highly productive, and energy-efficient technologies. Our model and numerical experiments with Comsol Multiphysics tools are a small step in the right direction.

\section{ACKNOWLEDGEMENTS:}

The authors gratefully acknowledge financial support by the European Regional Development Fund, Postdoctoral research aid Nr. 1.1.1.2/16/I/001 research application "Analysis of the parameters of the process of laser marking of new industrial materials for high-tech applications, Nr. 1.1.1.2/VIAA/3/19/474".

\section{REFERENCES}

[1] H. Zhao, D. R. White, and T. DebRoy, Current issues and problems in laser welding of automotive aluminium alloys. International Materials Reviews, 2013. 44(6): pp. 238-266.

[2] A. Haboudou, P. Peyre, A. Vannes and G. Peix, Reduction of porosity content generated during Nd:YAG laser welding of A356 and AA5083 aluminum alloys, Materials Science and Engineering: A, 363, 2003, pp. 40-52.

[3] J. Sánchez-Amaya, T. Delgado, L. González-Rovira and F. Botana, Laser welding of aluminum alloys 5083 and 6082 under conduction regime, Applied Surface Science, 255 (23), 2009, pp. 9512-9521.

[4] R. Ding, O. Ojo and M. Chaturvedi, Laser beam weld-metal microstructure in a yttrium modified directionally solidified Ni3Albase alloy, Intermetallics, 15, 2007, pp. 1504-1510.

[5] N. Dolchinkov, Investigation of the State of the Radiation Control Systems and the Actions of the Competent Authorities and the Population in the Event of a Change in the Radiation Background in Bulgaria, International Conference KNOWLEDGE-BASED ORGANIZATION, Vol. XXIV No 3, 2018, pp. 38-44.
[6] J. Yan, X. Zeng, M. Gao, J. Lai and T. Lin, Effect of welding wires on microstructure and mechanical properties of 2A12 aluminum alloy in CO2 laser-MIG hybrid welding, Applied Surface Science, 255 (16), 2009, pp. 7307-7313.

[7] Y. Shi, F. Zhonga, X. Li, S. Gong, and L. Chen, Effect of laser beam welding on tear toughness of a 1420 aluminum alloy thin sheet, Materials Science and Engineering: A, 465, 2007, pp. 153159.

[8] N. Abe, M. Tsukamoto, K. Maeda, K. Namba and J. Morimoto, Aluminum alloy welding by using a high power direct diode laser, Journal of Laser Applications, 18 (4), 2006, pp. 289-293.

[9] N. Dolchinkov, Practical Research of Marking and Cutting of Textiles with Increased Resistance, Using CO2 Laser, Journal of Physics: Conference Series , Volume 1681, 2020, 012014

[10] K. Howard, S. Lawson and Y. Zhou, Welding aluminum sheet using a highpower diode laser, Welding Journal 85 (5), 2006, pp. 101-110.

[11] L. Quintino, E. Assunção, 6 - Conduction laser welding, Editor(s): Seiji Katayama, In Woodhead Publishing Series in Electronic and Optical Materials, Handbook of Laser Welding Technologies, Woodhead Publishing, 2013, pp. 139-162.

[12] P. Narica, L. Lazov, A. Teilans, P.Grabusts, E. Teirumnieks and P. Cacivkins, Method for Color Laser Marking Process Optimization with the use of Genetic Algorithms. Environment. Technology. Resources. Proceedings of the $11^{\text {th }}$ International Scientific and Practical Conference. Volume II. - Rezekne, 2017. - pp. 101. 106. http://dx.doi.org/10.17770/etr2017vol2.2607

[13] L. Lazov, N. Angelov, E. Teirumnieks and E. Teirumnieka, Preliminary numerical analysis for the role of speed onto laser technological processes. Environment. Technology. Resources. Proceedings of the $12^{\text {th }}$ International Scientific and Practical Conference. Volume III. - Rezekne, 2019. - pp. 137. - 142. http://dx.doi.org/10.17770/etr2019vol3.4154

[14] L. Lazov, E. Teirumnieks, I. Draganov and N. Angelov, Numerical modeling and simulation for laser beam welding of ultrafinegrained aluminium. Laser Physics 31 (6), 066001. https://doi.org/10.1088/1555-6611/abf5d3 